\title{
Promising Clinical Results of the Universal Total Wrist Prosthesis in Rheumatoid Arthritis
}

\author{
P.J.T.S. van Winterswijk ${ }^{*}$ and P.A.G.M. Bakx
}

Department of Orthopedics, Maasstad Hospital, Rotterdam, The Netherlands

\begin{abstract}
The purpose of this study was to evaluate the results of the Universal Total Wrist prosthesis.
Seventeen wrist arthroplasties were performed in 15 patients using the Universal Total Wrist prosthesis. The 11 women and 4 men in the study group ranged in age from 45 to 86 years. Fourteen patients had rheumatoid arthritis and one had osteoarthritis. Follow up ranged from 20 to 74 months. Patients were evaluated for range of motion, with the Disabilities of the Arm, Shoulder, and Hand (DASH) survey and radiographically.

All range of motion values improved after surgery. Average postoperative motion was $29^{\circ}$ dorsiflexion, $38^{\circ}$ volar flexion, $7^{\circ}$ radial deviation and $17^{\circ}$ ulnar deviation. The DASH scores improved with $29 \%$. Pain score improved in all 15 patients. One prosthesis had to be removed due to component loosening of the carpal plate. The other cases showed no radiographic signs of loosening. One patient had an early prosthetic dislocation and was treated conservatively with success.
\end{abstract}

The Universal Total Wrist prosthesis provides a promising outcome in patients with rheumatoid arthritis.

Keywords: Universal total wrist prosthesis, rheumatoid arthritis, total wrist arthroplasty.

\section{INTRODUCTION}

Rheumatoid arthritis has a worldwide prevalence of approximately $1 \%[1]$. The disorder occurs three times more often in women and has a peak onset of between 40 and 60 years of age [2]. The wrist is the most common involved in the upper extremity in rheumatoid arthritis. Indications for surgery are progressive pain, deformity and loss of motion.

Although wrist arthrodesis effectively relieves pain and corrects deformity, the loss of motion may impair function considerably, especially when the shoulder, elbow, and hand also are affected by arthritis [3]. Total wrist arthroplasty (TWA) enhances the performance of daily activities and is preferred to arthrodesis by patients with rheumatoid arthritis $[4,5]$. Wrist arthroplasty however has a high complication rate, particularly wrist imbalance and implant loosening.

The Universal Total Wrist prosthesis (KMI, San Diego, CA) was designed to alleviate these problems through the use of a unique design for distal component fixation and an anatomically shaped, broad articulation (Fig. 1) [6]. The inventor of the Universal prosthesis reported good outcome and no distal component loosening [6].

The purpose of this study was to evaluate the results of the Universal Total Wrist prosthesis in rheumatoid arthritis.

\section{MATERIALS AND METHODOLOGY}

The Universal Total Wrist prosthesis (Fig. 1) has its fixation on the carpus with titanium screws. Minimal bone resection is needed to accommodate the prosthesis. The

*Address correspondence to this author at the Department of Orthopedics, Maasstad Hospital, Rotterdam, The Netherlands; Tel: +31 104130385; Fax: +31 102912138; E-mail: goaliepeter@hotmail.com carpal component is made from titanium and the carpal interface of polyethylene. It is ovoid and matches the cut surface of the carpal bones.

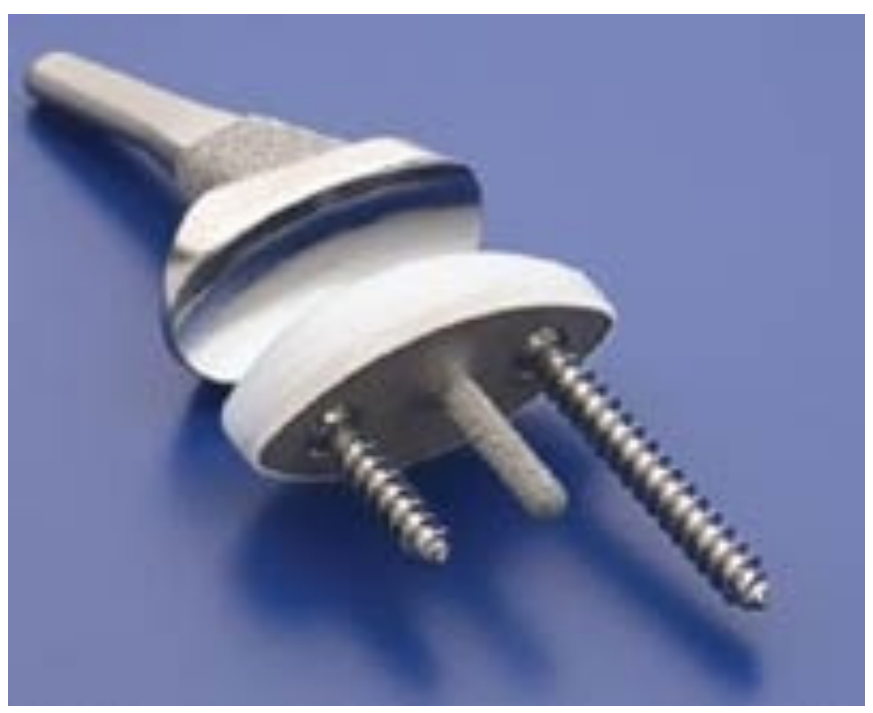

Fig. (1). Universal total wrist prosthesis.

\section{Indications}

Patients with chronic wrist pain unrelieved by adequate medical treatment by a qualified rheumatologist, or patients, who have severe wrist deformity that interferes with function, are candidates for total wrist arthroplasty. When there are combined deformities of the wrist and the fingers, wrist arthroplasty should be considered first.

Absolute contraindications include patients with active infection, a neurologically non-functioning hand and rupture 
of the radial wrist extensors. Relative contraindications are poor bone stock, young patients and manual labourers.

\section{Surgical Technique}

The appropriate size of implant is estimated preoperatively with X-Ray templates. General or regional anaesthesia and an arm tourniquet are used. A dorsal longitudinal incision is made over the wrist in line with the third metacarpal, and skin flaps are raised that include the subcutaneous tissues. The extensor carpi ulnaris compartment is opened along its volar margin, and the entire retinaculum is elevated radially up to the septum between the first and second extensor compartments.

An extensor tenosynovectomy is performed. The extensor carpi radialis brevis must be intact or reparable, and ideally the extensor carpi radialis longus is functional also.

A distally based rectangular flap of the dorsal wrist capsule is raised. The sides of the flap are made along the far medial and lateral aspects of the wrist. The capsule's proximal edge is raised in continuity with the dorsal capsule of the distal radioulnar joint and the periosteum over the distal $1 \mathrm{~cm}$ of the distal radius to create a broad long flap for closure over the prosthesis.

The distal ulna is resected at the level of the proximal margin of the sigmoid notch and saved for bone graft. The distal articular surface of the radius is resected. An osteotomy is made through the carpus through the capitate head, preserving most of the capitate and part of the scaphoid and triquetrum. A guide wire for a cannulated drill is inserted through the center of the capitate into the third metacarpal base. A hole is made for the distal component stem with the cannulated drill bit over this guide wire. The distal trial component is inserted. After predrilling, deep threaded osteointegrative screws are inserted into the carpus through the radial and ulnar holes of the distal component. The radial screw may cross the immobile second carpometacarpal joint, but the ulnar screw typically does not cross the mobile fourth or fifth carpometacarpal joints. The medullary canal of the radius is prepared with broaches. The broaches are inserted slightly dorsal to midaxis to avoid tracking along the palmar metaphyseal flare, which would cause palmar tilt of the implant. Defects in the palmar capsule are repaired, and its proximal edge is sutured to the radius if it was detached during the dissection. Trial components are inserted and the prosthesis is reduced. The wrist should rest in a neutral and balanced state.

Sutures are placed through the dorsal margin of the distal radius and the distal ulna for later capsule reattachment. The implants are inserted along with the distal component fixation screws. A polyethylene bearing of appropriate thickness is applied to the distal component; its thickness is chosen to achieve proper soft tissue tension and prosthetic stability. The remaining retinaculum is repaired over the extensor tendons to prevent bowstringing. The extensor carpi ulnaris tendon is brought dorsally over the distal ulna and held with a sling made from the retinaculum.

The wrist is immobilized in a bulky dressing and a volar arm splint. After two weeks the plaster splint is removed and a removable splint is given. The removable splint is for duration of four weeks. In these four weeks an exercise program is begun, including gentle active flexion, extension, and radial and ulnar deviation, pronation and supination. Patients have a limitation in lifting weights (5 kilograms) after surgery.

\section{RESULTS}

Between 2001 and 2006, 17 wrist arthroplasties were performed in 15 patients. The 11 women and 4 men in the study group had an average age of 64 years (range 45-84 years). Fourteen patients had rheumatoid arthritis and one had osteoarthritis. Two women had bilateral wrist arthroplasties. The average follow up was 46 months (range, 20-74 months). The indications were patients with chronic wrist pain unrelieved by adequate medical treatment by a qualified rheumatologist, or patients, who have severe wrist deformity that interferes with function.

Radiographs of the patients showed significant damage to the radiocarpal and midcarpal joints. Patients were evaluated preoperatively and postoperatively at 3,6 months and yearly, for range of motion and radiographically. The DASH (disabilities of the Arm, Shoulder and hand) [7] score list in Dutch translation, was filled in preoperative and at the latest follow-up visit (Table 1).

Table 1. Range of Motion Results (Mean)

\begin{tabular}{|l|c|c|c|c|c|}
\hline & $\begin{array}{c}\text { Dorsi } \\
\text { Flexion }\end{array}$ & $\begin{array}{c}\text { Volar } \\
\text { Flexion }\end{array}$ & $\begin{array}{c}\text { Radial } \\
\text { Deviation }\end{array}$ & $\begin{array}{c}\text { Ulnar } \\
\text { Deviation }\end{array}$ & DASH \\
\hline \hline Preoperative & 21 & 30 & 5 & 12 & 91 \\
\hline Postoperative & 29 & 38 & 7 & 17 & 65 \\
\hline
\end{tabular}

Standard radiographs were obtained at each postoperative evaluation. The radiographic parameters assessed were implant alignment and fit, screw positioning and implant loosening.

Al range of motion values improved after surgery (Table 1). The mean postoperative motion was: $29^{\circ}$ dorsiflexion, $38^{\circ}$ volar flexion, $7^{\circ}$ radial deviation and $17^{\circ}$ ulnar deviation. The DASH scores improved with a mean of $29 \%$. Pain scores improved in all patients. Postoperative $88 \%$ did not have any pain and $12 \%$ had moderate pain. Three of the 17 TWA were on the non dominant side.

In one patient the prosthesis had to be removed due to loosening of the carpal plate and one patient had early prosthetic dislocation and was treated conservatively with a cast for six weeks with success. In 2 other patients there was a suboptimal placement of the prosthesis. Both patients had no complaints and there was no migration during follow up.

None of the radiographs showed prosthetic loosening (Figs. 2, 3). In one patient one screw was not placed in the bone. Despite the wrong placement there are no problems with the stability of the carpal plate.

There were no infections or wound problems in our series.

One patient with osteoarthritis was treated. This patient had an improved range of motion and pain relief, but his improvement was not as good as in patients with rheumatoid arthritis. Patients who were operated on the dominant side 
were more satisfied than patients who were operated on the non-dominant side.

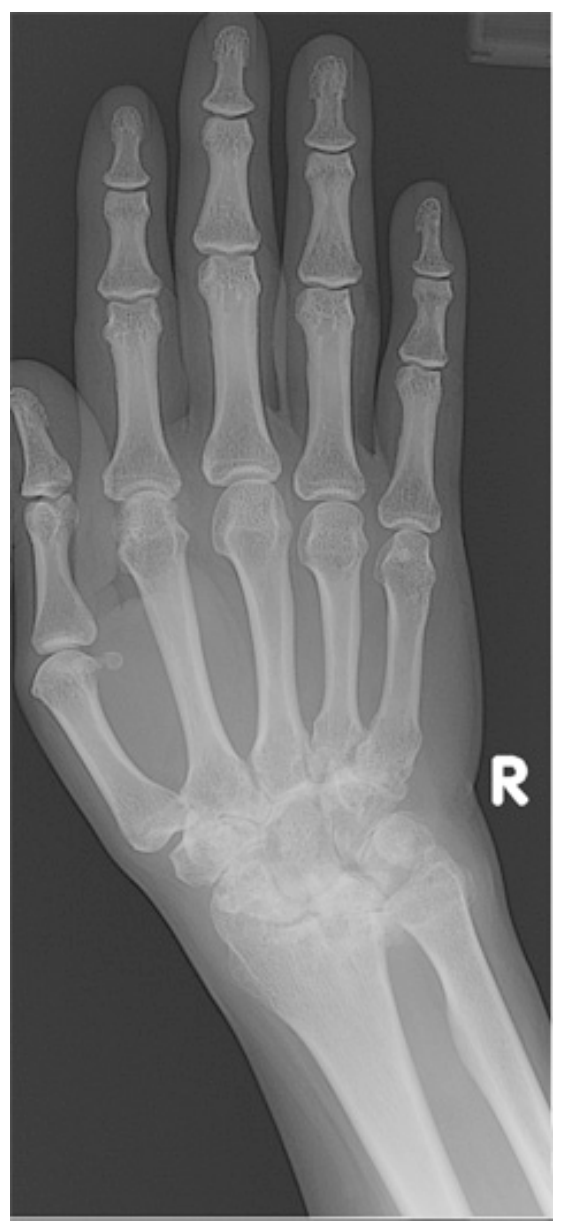

Fig. (2). Preoperative radiograph.

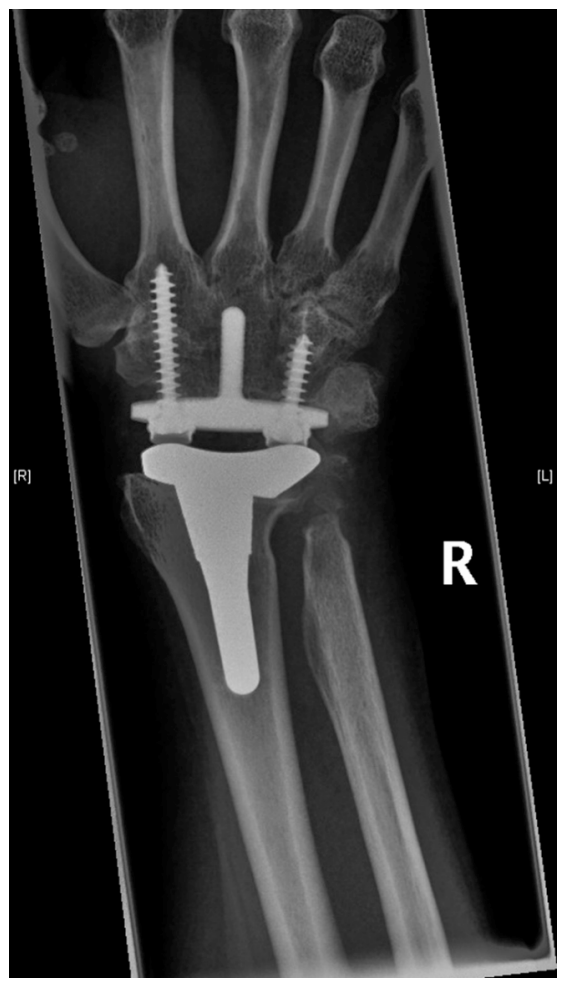

Fig. (3). Postoperative radiograph.

\section{DISCUSSION}

The first total wrist arthroplasty was performed 1890 by Thermistokles Gluck [8]. Swanson designed the first implant made of silicone [9]. Early results generally were gratifying with good pain relief and acceptable range of motion [4]. However, longer follow up revealed a high incidence of implant breakage, reaching $52 \%$ at 72 months $[10,11]$.

Biaxal (Depuy, Warsaw, Ind.,) [12, 13], Meuli (Sulzer Orthopaedics Ltd., Winterthur, Switzerland) [14-16], Volz (Howmedica Company, Rutherford, NJ, USA) [17-19], en Trispherical (Osteonics, Allendale, NJ, USA) $[20,21]$ are the most commonly used devices in North America. Problems with this prosthesis are implanting loosening, periprosthetic bone resorption and wrist imbalance.

The Universal Total Wrist prostheses was designed by Menon to alleviate these problems [6]. In his first report of 37 Universal prostheses with a mean follow up of 6.7 years, no case demonstrated radiographic evidence of distal implant loosening [6]. Similar to other prostheses, the Universal implant provided consistently good pain relief $(90 \%)$ and a functional range of motion. Average postoperative motion was $36^{\circ}$ extension, $41^{\circ}$ flexion, $7^{\circ}$ radial deviation en $13^{\circ}$ ulnar deviation. Dislocation was the most common complication, with 5 occurring in the first 37 cases.

The initial higher incidence of dislocation was attributed by Menon [6] lack of availability of different implant sizes and thickness of the polyethylene inserts at that time. Menon [6] criticised himself for excessive bone resection in the early cases.

A prospective study of 22 Universal prostheses with 1 tot 2 year follow-up demonstrated results similar to Menon's. Patients achieved an average of $41^{\circ}$ flexion and $35^{\circ}$ extension [3]. The DASH score improved 24 points in 2 years. Three $(14 \%)$ prostheses were unstable and required further treatment. A further multicenter study of 82 patients showed good results at 1 to 5 year follow-up. Dislocation continued to occur with a $9 \%$ overall incidence and distal component loosening occurred in 4 patients [22].

Results in our series show similar results as seen in literature $[3,6,22]$. One patient had carpal loosening and 1 patient had early postoperative dislocation. The dislocation was treated conservatively with success. There was no infection postoperatively. All patients were satisfied with the pain relief and $88 \%$ did not have any pain postoperatively. Range of motion improved, but the most promising results were pain reduction and improved DASH score. We treated one patient with osteoarthritis. Despite his range of motion improvement and pain relief he was not as satisfied as patients with rheumatoid arthritis.

Patients who were operated on the dominant side were more satisfied than patients who had a TWA on the non-dominant side. Three patients already had an arthrodesis on one side. These patients were more satisfied with the Universal Total wrist prostheses. The only limitation that we give patients with a TWA is a lifting one from maximal 5 kilograms.

\section{CONCLUSION}

The Universal Total Wrist prosthesis provides a promising outcome in patients with rheumatoid arthritis. 


\section{REFERENCES}

[1] Wolfe AM, Kellgren JH, Masi AT. The epidemiology of rheumatoid arthritis: A review. II. Incidence and diagnostic criteria. Bull Rheum Dis 1968; 19(3): 524-9.

[2] Alarcon GS. Epidemiology of rheumatoid arthritis. Rheum Dis Clin North Am 1995; 21(3): 589-604.

[3] Divelbiss BJ, Sollerman C, Adams BD. Early results of the Universal total wrist arthroplasty in rheumatoid arthritis. J Hand Surg Am 2002; 27(2): 195-204.

[4] Goodman MJ, Millender LH, Nalebuff ED, Phillips CA. Arthroplasty of the rheumatoid wrist with silicone rubber: an early evaluation. J Hand Surg Am 1980; 5(2): 114-21.

[5] Vicar AJ, Burton RI. Surgical management of the rheumatoid wrist--fusion or arthroplasty. J Hand Surg [Am] 1986; 11(6): 7907.

[6] Menon J. Universal Total Wrist Implant: Experience with a carpal component fixed with three screws. J Arthroplasty 1998; 13(5): $515-23$.

[7] In: http://www.dash.iwh.on.ca/ 2003.

[8] Ritt MJ, Stuart PR, Naggar L, Beckenbaugh RD. The early history of arthroplasty of the wrist. From amputation to total wrist implant. J Hand Surg Br 1994; 19(6): 778-82.

[9] Swanson AB. Flexible implant arthroplasty for arthritic disabilities of the radiocarpal joint. A silicone rubber intramedullary stemmed flexible hinge implant for the wrist joint. Orthop Clin North Am 1973; 4(2): 383-94.

[10] Jolly SL, Ferlic DC, Clayton ML, Dennis DA, Stringer EA. Swanson silicone arthroplasty of the wrist in rheumatoid arthritis: A long-term follow-up. J Hand Surg Am 1992; 17(1): 142-9.
[11] Stanley JK, Tolat AR. Long-term results of Swanson silastic arthroplasty in the rheumatoid wrist. J Hand Surg Br 1993; 18(3): 381-8.

[12] Cobb TK, Beckenbaugh RD. Biaxial total-wrist arthroplasty. J Hand Surg Am 1996; 21(6): 1011-21.

[13] Cobb TK, Beckenbaugh RD. Biaxial long-stemmed multipronged distal components for revision/bone deficit total-wrist arthroplasty. J Hand Surg Am 1996; 21(5): 764-70.

[14] Meuli HC. Meuli total wrist arthroplasty. Clin Orthop Relat Res 1984; 187: 107-11.

[15] Meuli HC, Fernandez DL. Uncemented total wrist arthroplasty. J Hand Surg Am 1995; 20(1): 115-22.

[16] Meuli HC. Total wrist arthroplasty. Experience with a noncemented wrist prosthesis. Clin Orthop Relat Res 1997; 342: 77-83.

[17] Volz RG. The development of a total wrist arthroplasty. Clin Orthop Relat Res 1976; 116: 209-14.

[18] Volz RG. Total wrist arthroplasty. A clinical review. Clin Orthop Relat Res 1984; 187: 112-20.

[19] Menon J. Total wrist replacement using the modified Volz prosthesis. J Bone Joint Surg Am 1987; 69(7): 998-1006.

[20] Figgie MP, Ranawat CS, Inglis AE, Sobel M, Figgie HE, 3rd. Trispherical total wrist arthroplasty in rheumatoid arthritis. J Hand Surg Am 1990; 15(2): 217-23

[21] Figgie HE, 3rd, Ranawat CS, Inglis AE, Straub LR, Mow C. Preliminary results of total wrist arthroplasty in rheumatoid arthritis using the Trispherical total wrist arthroplasty. J Arthroplasty 1988; 3(1): 9-15.

[22] Adams BD. Total wrist arthroplasty. Orthopedics 2004; 27(3): 27884

(C) van Winterswijk and Bakx et al.; Licensee Bentham Open.

This is an open access article licensed under the terms of the Creative Commons Attribution Non-Commercial License (http://creativecommons.org/licenses/by-nc/ $3.0 /$ ) which permits unrestricted, non-commercial use, distribution and reproduction in any medium, provided the work is properly cited. 